\title{
Optische Strukturuntersuchung flüssiger Schäume
}

D as Unternehmen Krüss nutzte die European Coatings Show 2013 in Nürnberg, um dem Fachpublikum für den Dynamic Foam Analyzer DFA100 ein Modul zur optischen Strukturuntersuchung flüssiger Schäume zu präsentieren. Dieses Instrument ermittelt per Bildanalyse die Anzahl, Größe und Größenverteilung der Schaumblasen eines im Gerät kontrolliert erzeugten Schaums. Dabei bedient sich das Schaumstrukturmodul einer höhenverstellbaren Kamera mit schneller Bildfolge, um die zeitlichen Strukturveränderungen des Schaums zu erfassen. So wird die innere Destabilisierung des Schaums sichtbar, lange bevor er zerfällt.

Weitere Infos: www.kruss.de

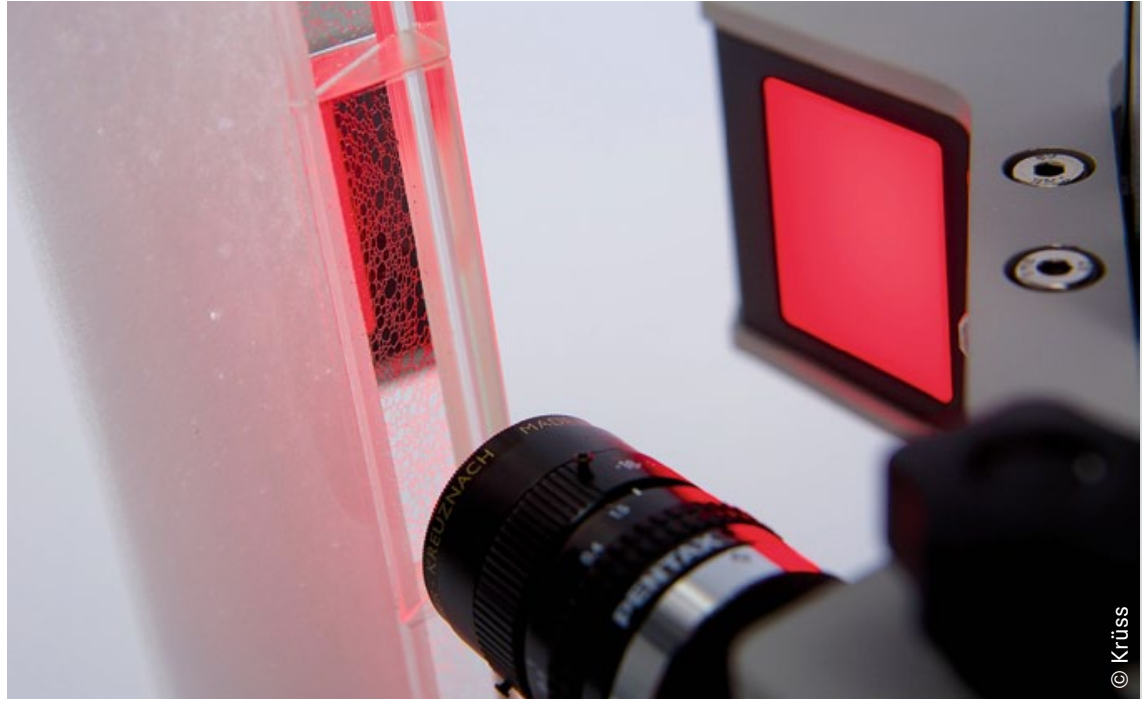

Eine höhenverstellbare Kamera mit schneller Bildfolge erfasst die zeitlichen Strukturveränderungen des kontrolliert erzeugten Schaums.

\section{Neue PUR-Klebstoffe für die grafische Industrie}

Dlanatol hat eine eigene PUR-Produktfamilie entwickelt, die speziell die Anforderungen der grafischen Industrie erfüllt. Neben dem Standardprodukt Planatol 2880 PUR, einem Rückenleim, der auch auf schwierigen Papieren haftet, hat das Unternehmen mit Planatol 1142 PUR einen innovativen Klebstoff im Angebot, der sich durch seine Festigkeiten auszeich-

\section{Kleben von Glas}

$D_{p}^{y}$ max Europe hat sein Produktportfolio im Bereich der UV-Klebstoffe für Glas um den vielseitig einsetzbaren Klebstoff Ultra Light-Weld 431 erweitert. Dieses Material widersteht erhöhten Temperaturen sowie Luftfeuchtigkeit, ohne an Haftung und Flexibilität zu verlieren. Es härtet mit UV- und sichtbarem Licht aus und kann sowohl mit herkömmlichen UVGeräten als auch mit dem Dymax BlueWave LED Prime UVA Punktstrahler ausgehärtet werden. Der Klebstoff fin- net. Gleichzeitig zeigt dieser Klebstoff ein sehr gutes Aufschlagverhalten (Lay Flat), sodass er sich ideal für den Einsatz in Fotobüchern, Bildbänden oder anderen hochwertigen Büchern eignet, bei denen ein flaches Erscheinungsbild von Bedeutung ist.

Dem zunehmenden Verlangen nach Energieeinsparungen und der Reduzierung von Emissionen im Betrieb trägt

det idealerweise Einsatz im Bereich von Glas-Glas- oder Glas-Metall-Verklebungen in der Möbel-, Beleuchtungs- sowie Verpackungssindustrie. Er ermöglicht schnelle Verklebungen mit einer hohen Haftkraft auf Glas, Metall, einer Vielzahl von Kunststoffen sowie Keramik und FR4 und ist RoHS konform gemäß den Richtlinien 2002/95/EC und 2003/11EC.

Weitere Infos: Dymax Europe GmbH, Wiesbaden,www.dymax.com, info@dymax.com schließlich das Produkt Planatol 1265 PUR Rechnung. Dieser Polyurethanklebstoff kann bei Arbeitstemperaturen von unter $100^{\circ} \mathrm{C}$ uneingeschränkt verwendet werden.

Weitere Infos: Planatol Adhesive $\mathrm{GmbH}$, info@planatol.de, Tel.: +49 8031-720-0, www.planatol.de

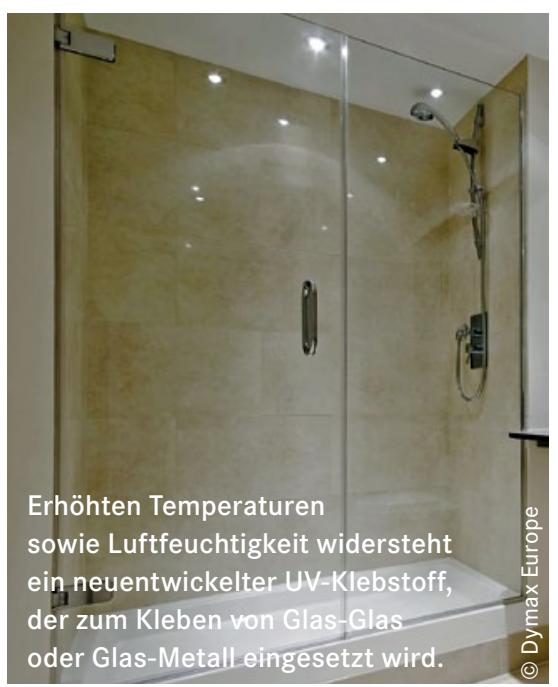

